\title{
EDITORIALS
}

\section{The Hospitalist Field Turns 15: New Opportunities and Challenges}

Robert M. Wachter, MD

Division of Hospital Medicine, Department of Medicine, University of California, San Francisco, San Francisco, California.

Disclosure: Nothing to report.

Additional Supporting Information may be found in the online version of this article.

Many people date the start of the hospitalist field to my 1996 New England Journal of Medicine article, ${ }^{1}$ which first introduced the concept to a broad audience. That makes 2011 the field's 15th year, and-if you have kids-you know this is a tough and exciting age. The cuteness of childhood has faded, and bad decisions can no longer be excused as youthful indiscretions.

That's an apt metaphor for our field as we celebrate our 15th birthday. We are now an established part of the health care landscape, with a clear place in the House of Medicine. All of the measures of a successful specialty are ours: a thriving professional society, high-quality training programs, increasingly robust research, a flourishing journal, and more. The field has truly arrived.

But these successes are also tempered by several challenges that have become more evident in recent years. In this article, I'll reflect on some of these successes and challenges.

\section{The Hospitalist Field's Successes and Growth}

In our 1996 article, Goldman and $\mathrm{I}^{1}$ wrote about the forces promoting the hospitalist model:

It seems unlikely...that high value care can be delivered in the hospital by physicians who spend only a small fraction of their time in this setting. As hospital stays become shorter and inpatient care becomes more intensive, a greater premium will be placed on the skill, experience, and availability of physicians caring for inpatients.

When we cited the search for value as a driving force in 1996, we were a bit ahead of our time, since there was relatively little skin in this game at the time. Remember that when our field launched, none of these value-promoting forces existed: robust unannounced hospital inspections by the Joint Commission, public reporting of quality data, pay for performance, "no pay for errors," state reporting of sentinel events, and more. In other words, until recently, neither a hospital's income stream nor its reputation was threatened by poor performance.

But this landscape is undergoing a sea change. By 2015, fully $9 \%$ of a hospital's Medicare reimbursements will be at risk through a variety of initiatives, including value-based purchasing and meaningful use standards. And private payers are beginning to replicate Medicare's standards, par- ticularly when they perceive that they may lead to both improved quality and lower costs.

Hospitals and health systems increasingly recognize how indispensable hospitalists can be as they demonstrate that their presence improves value. But this is only one of the forces driving the field-already the fastest growing specialty in medical history - to even higher levels of growth. These others include: the exodus of primary care physicians from the hospital, the fact that the specialists have left the building, comanagement of nonmedical patients, new opportunities in systems leadership, and dealing with housestaff duty hours reductions. I'll say a word about each.

\section{The Exodus of Primary Care Physicians}

In the early days of our field, one of the major sources of pushback was the desire of many primary care doctors to continue managing their own inpatients. Beginning a decade ago, this pressure began to abate, as many primary care physicians began to recognize the potential advantages of working with hospitalists. ${ }^{2}$

Over the next several years, I predict that the growth in the patient-centered medical home model $^{3}$ - with the physician's new responsibilities to provide comprehensive patient-centered care-will make it even less likely that primary care doctors will have the time to manage their own inpatients. Luckily, information systems now being installed throughout the country (fueled by federal subsidies) will lead to unprecedented connectivity between the inpatient and outpatient worlds, ${ }^{4}$ hopefully resulting in improving handoffs.

Moreover, the increasing scrutiny of, and upcoming penalties for, high readmission rates are driving hospitals and clinics into creating more robust systems of care to improve inpatient-outpatient communications. The bottom line is that the main Achilles heel of hospitalist systems-the handoff at hospital admission and discharge-should improve over the next few years, making it easier than ever for primary care doctors to forego hospital care without losing track of critical patient information.

\section{The Specialists Have Left the Building}

One of the more interesting phenomena in the recent history of the hospitalist field is the growth of what I call "hyphenated hospitalists": neurology hospitalists, ob-gyn 


\section{TABLE 1. Questions to Ask in Determining Whether a Specialty Hospitalist Field Might Be Successful}

1) Is the number of inpatients who require the services of that specialty (either for consults or principal care) large enough to justify having at least one doctor in the house during daytime?

2) Is the specialist frequently needed to see an inpatient urgently?

3) Under the usual model of mixed inpatient and outpatient care, is the specialist frequently busy in the office, operating room, or procedural suite at times where they are urgently needed in the hospital (see \#2)?

4) Has the field become sub-sub specialized, such that many covering physicians are now uncomfortable managing common acute inpatient problems (i.e., the headache neurologist asked to handle an acute stroke)?

NOTE: Adapted with permission from: The New Home Team: The Remarkable Rise of the Hyphenated Hospitalist. Wachter's World blog, January 16, 2011. Available at: http://tinyurl.com/4h2jy7e.

\section{TABLE 2. System Leadership Roles Held by UCSF Hospitalists}

Role
Associate Chief Medical Officer
Associate Medical Director for Information Technology
Associate Chair for Quality and Safety
Director of Quality and Patient Safety
Associate Medicine Residency Director (two people)
Director of Medical Student Clerkships
Director of Patient Safety/Quality Programs

Abbreviations: FTE, full-time equivalent; UCSF, University of California, San Francisco.
Works for Whom?

Approximate \% FTE

Medical Center

Medical Center

Department of Medicine

Department of Neurosurgery

Department of Medicine

Department of Medicine

Office of Graduate Medical Education, School of Medicine
$80 \%$

$80 \%$

$50 \%$

$50 \%$

$30 \%$ (for each)

$25 \%$

$25 \%$

Total FTEs: 3.7 hospitalists, surgical hospitalists, and the like. The forces promoting these models are similar to those that catalyzed the hospitalist model: the recognition that bifurcating inpatient and outpatient care sometimes makes sense when several conditions are met (Table 1).

The emergence of hyphenated hospitalists raises all sorts of questions for the hospitalist field, many of which I have addressed elsewhere. ${ }^{5}$ But the bottom line is that the growth of specialty hospitalists may help create a new hospital "home team"-a group of dedicated inpatient physicians spanning virtually every specialty who share best practices, work together on systems improvements, and operate under similar accountabilities. This development may well be the most exciting one in the field's recent history.

\section{Comanagement of Nonmedical Patients}

The same forces that led to the emergence of the hospitalist field are also catalyzing the growth of hospitalist comanagement programs. There is a shortage of general surgeons, and in teaching hospitals, there are fewer surgical residents available to help provide floor-based pre- and post-operative care. And surgical patients are under the same value pressures as medical patients, with increasing public reporting of quality processes and outcomes and new pay for performance programs coming on line. Although the evidence of benefit is mixed, ${ }^{6-8}$ many hospitalists are finding that increasing parts of their work involve comanagement.

Comanagement raises several issues, all of which need to be addressed. How do we define clear boundaries between what the hospitalist does and what the specialist does? Comanagement programs, to be effective, need very clear rules of engagement and open lines of communication to work through inevitable conflicts. ${ }^{6}$ How does the money flow? Most hospitalist programs receive hospital support, but it is legitimate to wonder whether the specialists, particularly surgeons, should chip in to support the program, particularly if they continue to collect a global case rate that was predicated on their provision of pre- and post-operative care. How do comanagement programs and specialty hospitalist programs interrelate, and what are the relative advantages and disadvantages of each? To my mind, programs that meet the conditions outlined in Table 1 probably would do well to start a specialty hospitalist program, assuming that they can find high-quality specialists to staff it. But there will be myriad variations on these themes. In my hospital, for example, we have both neurohospitalists and medical hospitalists who co-manage neurosurgery patients.

\section{New Opportunities in Systems Leadership}

The growth of the hospitalist field will partly come from individuals who begin their careers performing clinical work, but who transition over time to managerial and leadership roles. This is a natural transition: Who better than a hospitalist to help organize and deliver educational programs, manage clinical operations, implement information technology systems, or lead quality, safety, or utilization management efforts? Of course, as hospitalists assume these roles, others need to take their places covering their clinical shifts.

This might seem like a relatively unimportant driver of personnel growth, but in more advanced systems, it can become a major one. Table 2 lists the faculty in my Division of Hospital Medicine at the University of California, San 
Francisco (UCSF) who have major institutional (i.e., nondivisional) roles. These roles, spread across eight faculty, account for 3.7 full-time equivalents (FTEs).

\section{Dealing with New ACGME Regulations}

In 2003, the Accreditation Council for Graduate Medical Education (ACGME) issued its first housestaff duty hours reductions (limiting housestaff to a maximum of 80 hours per week, with no single shift lasting longer than 30 hours). This reduction led to the development of nonteaching services in most teaching hospitals; the vast majority of such programs have hospitalists at their core.

In July 2011, new ACGME regulations go into effect, ${ }^{10}$ which will further cut the availability of housestaff to cover clinical services. Although the 80-hour weekly limit remains, intern shifts are now limited to 16 hours, meaning that the traditional "long call" system involving interns must be replaced by a shift-based system. Like the earlier changes, these new regulations are leading to additional hospitalist growth in the nation's teaching hospitals. By the time the changes are fully implemented, many hospitalist programs will have half or more of their hospitalist FTEs devoted to covering patients previously cared for by residents.

\section{Challenges for Hospitalist Programs}

These powerful forces promoting the growth in the hospitalist field continue to ensure that hospitalists are in high demand. As a practical matter, this has resulted in increasing salaries and improved job conditions for hospitalists.

But this growth brings many challenges. Many hospitalist programs are poorly managed, often because the leaders lack the training and experience to effectively run such a rapidly growing and complex enterprise. One manifestation of these leadership challenges is that schedules are often created around the convenience and desires of the physicians rather than the needs of the patients. For example, the increasingly prevalent seven-days-on, seven-days-off schedule often leads to burnout and a feeling by the hospitalists that they are working too hard. Yet many groups are unwilling to consider modifications to the schedule that might decrease the intensity, if the cost is fewer days off.

On the other hand, some groups pay little attention to patient continuity in constructing their schedules. I know of programs that schedule their hospitalists in 24-hour shifts (followed by a few days off), which means that admitted patients will see a different hospitalist every day. I see this as highly problematic, particularly because the most common complaint I hear from patients about hospitalist programs is that "I saw a different doctor every day."

Many of the field's challenges stem from hospitalists' near-total dependency on hospital funding to create sustainable job descriptions. ${ }^{11}$ While I continue to believe that this bit of financial happenstance has been good for both hospitalists and hospitals-since it has driven uncommon degrees of interdependency and alignment-it does mean that a difficult budget battle is virtually assured every year. As hospital finances become tighter, one can expect these battles to grow even more heated. Speaking for hospitalists, I am not too worried about the outcomes of these battles, since hospitalists provide a mission-critical service at a fair price, there are no viable lower-priced replacements (expect perhaps for nonphysician providers such as nurse practitioners for the less-complex patients), and hospitalists are extraordinarily mobile-there are virtually no barriers for a hospitalist, or an entire group, to transfer to another institution. Nevertheless, it seems inevitable that these battles will leave scars, scars that may ultimately compromise the crucial collaboration that both hospitalists and hospitals depend on.

\section{The Bottom Line}

Even at age 15, an age at which many adolescents are irredeemably cynical, the hospitalist field retains much of its sense of limitless possibility and exuberance. This is not because things are perfect-they are not. Some hospitalist jobs are poorly constructed, some groups have poor leadership, some hospitalists are burning out, there are examples of spotty quality and collaboration, and hospitalists continue to have to work to earn the respect of colleagues and patients that other specialists take for granted.

That said, the field of hospital medicine remains uniquely exciting, in part because it is so tightly linked to the broader changes in the health care policy landscape. Many other specialties see the profound changes underway in health care as an existential threat to their professional values and incomes. Hospitalists, on the other hand, see these changes as raising the pressure on hospitals to deliver the highest quality, most satisfying, and safest care at the lowest cost. Framed this way, forward-thinking hospitalists quite naturally see these changes as yet another catalyst for the growth and indispensability of their field.

\section{Address for correspondence and reprint requests:}

Robert M. Wachter, MD, Department of Medicine, University of

California, San Francisco, 505 Parnassus, Room M-994, San

Francisco, CA 94143-0120; Telephone: 415-476-5632;

Fax: 415-502-5869; E-mail: bobw@medicine.ucsf.edu

Received 14 February 2011; revision received 21 February 2011; accepted 21 February 2011.

\section{References}

1. Wachter RM, Goldman L. The emerging role of "hospitalists" in the American health care system. N Engl J Med. 1996;335:514-517.

2. Auerbach AD, Aronson MD, Davis RB, Phillips RS. How physicians perceive hospitalist services after implementation: Anticipation vs reality. Arch Intern Med. 2003;163:2330-2336.

3. Carrier E, Gourevitch MN, Shah NR. Medical homes: Challenges in translating theory into practice. Med Care. 2009;47:714-722.

4. Bates DW, Gawande AA. Improving safety with information technology N Engl J Med. 2003;348:2526-2534.

5. The New Home Team: The Remarkable Rise of the Hyphenated Hospitalist. Wachter's World blog, January 16, 2011. Available at: http://tinyurl. com/4h2jy7e. Accessed February 12, 2011. 
6. Auerbach AD, Wachter RM, Cheng HQ, et al. Comanagement of surgical patients between neurosurgeons and hospitalists. Arch Intern Med. 2010; 170:2004-2010.

7. Huddleston JM, Long KH, Naessens JM, et al. Medical and surgical comanagement after elective hip and knee arthroplasty: A randomized, controlled trial. Ann Intern Med. 2004;141:28-38.

8. Sharma G, Kuo YF, Freeman J, Zhang DD, Goodwin JS. Comanagement of hospitalized surgical patients by medicine physicians in the United States. Arch Intern Med. 2010;170:363-368.
9. Josephson SA, Engstrom JW, Wachter RM. Neurohospitalists: An emerging model for inpatient neurological care. Ann Neurol. 2008;63:135-140.

10. Nasca TJ, Day SH, Amis ES Jr; ACGME Duty Hour Task Force. The new recommendations on duty hours from the ACGME Task Force. $N$ Engl J Med. 2010 Jul 8;363(2):e3. Epub 2010 Jun 23. PubMed PMID: 20573917. The website is here: http://www.nejm.org/doi/full/10.1056/NEJMsb1005800.

11. Quinn R. Elevated expectations. The Hospitalist. January 2011. Available at: http://www.the-hospitalist.org/details/article/972781/Elevated_Expectations.html. Accessed February 12, 2011. 